INVESTIGASI KASUS DIARE PADA

BALITA DI KOTA PALEMBANG TAHUN

2015-2016 DENGAN PENDEKATAN

SISTEM INFORMASI GEOGRAFIS

JKMA

Jurnal Kesehatan Masyarakat Andalas diterbitkan oleh:

Program Studi S-1 Kesehatan Masyarakat Fakultas Kesehatan Masyarakat Universitas Andalas p-ISSN 1978-3833 e-ISSN 2442-6725

12(2)90-96

Diterima 4 April 2018

Disetujui 26 Agustus 2018

Dipublikasikan 1 September 2018

@2018 JKMA

http://jurnal.fkm.unand.ac.id/index.php/jkma/

Amrina Rosyada $^{1} \otimes$, Dini Arista Putri ${ }^{1}$, Nur Alam Fajar ${ }^{1}$

${ }^{1}$ Fakultas Kesehatan Masyarakat, Universitas Sriwijaya, Indralaya, Sumatra Selatan

\begin{abstract}
Abstrak
Kasus diare pada balita masih menjadi salah satu penyebab kematian balita terbanyak. Berdasarkan laporan dari Dinas Kesehatan Kota Palembang, terdapat peningkatan jumlah kasus diare di daerah perkotaan antara tahun 2015-2016. Terdapat satu puskesmas di daerah perkotaan yang mengalami peningkatan 4 kali lipat antara tahun 2015-2016. Tujuan dari penelitian ini untuk menginvestigasi penyebab peningkatan kasus diare di wilayah kerja puskesmas Punti Kayu yang termasuk wilayah perkotaan. Penelitian ini merupakan penelitian yang bersifat deskriptif kualitatif dengan menggunakan data sekunder, wawancara dengan 3 petugas puskesmas serta observasi wilayah. Penelitian di lakukan di wilayah kerja Puskesmas Punti Kayu Palembang. Hasil akan dianalisis dengan pendekatan SIG untuk menghasilkan peta distribusi spasial kasus diare pada balita antara tahun 2015-2016 di kota Palembang. Selain itu, metode Content Analysis untuk menginvestigasi penyebab peningkatan kasus. Setelah dianalisis diketahui bahwa antara tahun 2015-2016 peningkatan kasus tertinggi berada pada kecamatan Alang-alang Lebar dimana terdapat Puskesmas Punti Kayu. Penyebab peningkatan jumlah kasus ini karena adanya pasien non wilayah kerja puskesmas Punti Kayu seperti Sukarame, Talang Kelapa, dan Sosial seiring dengan maraknya penggunaan Jaminan Kesehatan Nasional. Selain itu, promosi kesehatan ke rumah-rumah penduduk kebanyakan mendapat penolakan. Perlunya adanya inovasi dalam peningkatan kesadaran tentang pentingnya sanitasi lingkungan pribadi serta perlunya pemisahan pelaporan antara pasien wilayah kerja dan non wilayah kerja agar diketahui dengan jelas berapa banyak kasus di daerah tersebut yang perlu diintervensi oleh pihak puskesmas.
\end{abstract}

Kata Kunci: Balita, Diare, Lingkungan, Peta

\title{
INVESTIGATION DIARRHEA CASES IN CHILD IN PALEMBANG CITY 2015-2016 WITH GEOGRAPHIC INFORMATION SYSTEM APPROACH
}

\begin{abstract}
Diarrhea cases in children under five are still one of the causes of the death of most children. Based on reports from the Palembang City Health Office, there is an increase in the number of diarrhea cases in urban areas between 2015-2016. There is one health center in urban areas that has a 4-fold increase between 2015-2016. The purpose of this study was to investigate the causes of an increase in diarrhea cases in the working area of Punti Kayu health center which included urban areas. This research is a qualitative descriptive study using secondary data, interviews with 3 health center staff and regional observations. The research was conducted in the working area of Punti Kayu Palembang Health Center. The results will be analyzed using the GIS approach to produce a map of the spatial distribution of diarrhea cases in children between 2015-2016 in the city of Palembang. In addition, the Content Analysis method to investigate the causes of increased cases. After analysis, it was found that between 2015-2016 the highest increase in cases was in Alang-alang sub-district where there was the Punti Kayu Health Center. The cause of the increase in the number of cases is due to the presence of non-working areas in Punti Kayu health centers such as Sukarame, Talang Kelapa, and Social along with the widespread use of National Health Insurance. In addition, health promotion to the homes of most residents was rejected. The need for innovation in raising awareness about the importance of private sanitation and the need for separation of reporting between patients in the work area and non working areas so that it is clear how many cases in the area need to be intervened by the health care
\end{abstract}

Keywords: Children, Diarrhea, Environtment, Map

$\nabla$ Korespondensi Penulis:

Fakultas Kesehatan Masyarakat, Universitas Sriwijaya, Indralaya, Sumatra Selatan

Email: arosyadaeffendy@gmail.com Telepon/HP: 0812724623000 


\section{Pendahuluan}

Penyakit diare adalah penyakit infeksi yang memiliki ciri-ciri buang air besar encer dan terjadi 4 kali sehari atau lebih, baik disertai lendir dan darah maupun tidak. Penyakit menular ini dapat menimbulkan gangguan malabsorpsi zat gizi dalam makanan dan dehidrasi. Kondisi ini yang dapat menimbulkan bahaya khususnya pada anak-anak dibawah 5 tahun karena dapat menimbulkan kematian apabila tidak ditangani dengan cepat. Penelitian diare pada anak-anak ditemukan fakta bahwa $80 \%$ kematian terjadi pada anak berusia kurang dari dua tahun. ${ }^{(1,4,5)}$

Morbiditas dan mortalitas penyakit diare masih menduduki angka yang cukup tinggi khususnya pada anak-anak dimana daya tahan tubuh yang belum menjalankan fungsinya dengan optimal. Kejadian diare di Provinsi Sumatera Selatan pada tahun 2014 yang berhasil ditangani sekitar $97,16 \%$ dari perkiraan diare di fasilitas kesehatan 174.735. Hal ini berarti masih ada 2,84\% kejadian diare di tahun 2014 yang belum tertangani. (8) Faktor resiko kejadian diare erat kaitannya dengan lingkungan penderita terkait penggunaan air, sampah, serta penggunaan jamban. Faktor lingkungan ini berhubungan dengan diare melalui praktek sanitasi yang dilakukan individu. $(14,16)$

Wilayah kota Palembang sebagian terdiri dari daerah sungai dan rawa. Daerah rawa pada umumnya dicirikan oleh terbentuknya cekungan yang lebih luas, dengan kedalaman relative dangkal, genangan air yang relatif. Sedangkan daerah aliran sungai, termasuk di dalamnya adalah dataran limpahan banjir (fload plain), yang merupakan bentuk cekungan yang memanjang, berlembah, dan biasanya lebih dalam, serta memperlihatkan pula adanya aliran tertentu, yang dibentuk oleh sungai utama, beserta anak-anak sungainya. (2) Jumlah masyarakat yang tinggal di daerah sungai dan rawa juga cukup banyak sehingga aktivitas sehari-hari seperti mandi, mencuci, buang air besar, dan lain-lain dilakukan disekitar sungai dan rawa. Dan juga terdapat beberapa pabrik seperti pabrik minyak dan pabrik pupuk. Hal ini dapat membuat air sungai dan rawa menjadi tercemar sehingga ketika mereka menggunakannya dapat menjadi sumber penyakit. Sehingga masyarakat yang tinggal di kota Palembang khususnya anakanak, memiliki kerentanan yang cukup tinggi terhadap kasus diare. ${ }^{(13)}$

Diare masih merupakan masalah kesehatan balita yang perlu perhatian serius dari berbagai pihak terkait dampaknya yang dapat menimbulkan dehidrasi hingga kematian pada balita. Pada penelitian mengenai data dinas kesehatan Palembang tentang diare balita tahun 2016 diketahui bahwa data dari dinas kesehatan terkait jumlah kasus diare di kota Palembang didominasi balita di daerah kecamatan Ilir Timur 1 yang mencakup daerah Dempo, Ariodillah, dan TalangRatu. Ketiga daerah ini termasuk wilayah perkotaan yang penduduknya sebagian besar sudah mempunyai jamban keluarga dan sumber air minum dari PDAM. Hasil penelitian menunjukkan bahwa daerah ini memiliki kasus diare yang tinggi karena sumbangan kasus non wilayah kerja puskesmas ${ }^{(12)}$. Sehingga upaya program pencegahan diare tidak berjalan dengan optimal karena upaya yang dilakukan berbasis wilayah sedangkan kasus kebanyakan berasal dari non wilayah kerja. Selain itu, puskesmas masih mengandalkan posyandu dan belum langsung terjun kemasyarakat. Sedangkan kebanyakan ibu tidak membawa balitanya lagi ke posyandu setelah imunisasi dasar lengkap dilakukan. Pada penelitian ini, peneliti ingin melihat perubahan pola persebaran dari diare di kota Palembang antara tahun 2015-2016 dengan memvisualisasikan data ke dalam bentuk peta. Data visualisasi diare balita ini tidak terdapat di laporan profil kesehatan Kota Palembang hanya diare pada semua umur. Sedangkan diare dapat menjadi kematian terbanyak pada usia bayi dan balita. Selain itu, penelitian ini bertujuan untuk menginvestigasi penyebab terjadinya kasus tersebut dari segi lingkungan (sampah, sumber air, dan penggunaan jamban) dan fasilitas kesehatan. Investigasi kasus diare pada balita ini dilakukan untuk menjamin kefektifan program diare yang dilakukan tepat sasaran dan dilakukan dengan tepat.

\section{Metode}

Penelitian ini merupakan penelitian yang bersifat deskriptif kualitatif. Metode penelitian 
Gambar 1. Peta Jumlah Kasus Diare pada Balita Tahun 2015

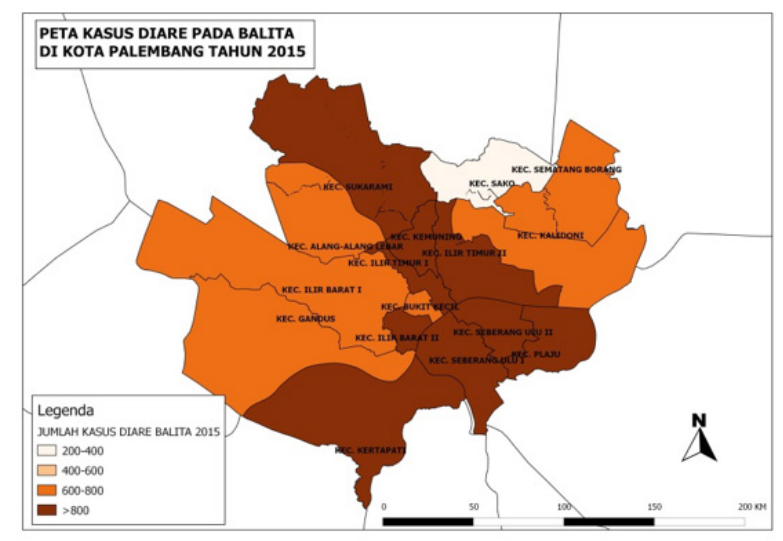

deskriptif merupakan salah satu metode penelitian yang memberikan tujuan untuk memberikan gambaran mengenai suatu objek maupun keadaan secara objektif, sistematis, dan akurat. (15) Penelitian ini berlokasi di wilayah kerja puskesmas Punti Kayu yaitu pada puskesmas dengan kasus diare tertinggi tahun 2016. Penelitian akan dilakukan selama 6 bulan yaitu Juli 2017 sampai Desember 2017 dengan waktu pengumpulan data pada Juli-September 2017. Penelitian ini menggunakan metode pengumpulan data kualitatif yaitu wawancara mendalam pemegang program diare, penanggung jawab kesehatan lingkungan dan bagian promosi kesehatan puskesmas Punti Kayu, kemudian melakukan observasi langsung terhadap kondisi lingkungan wilayah kerja dan melakukan telaah dokumen untuk investigasi indikasi pasien non wilayah kerja puskesmas. Langkah-langkah pengumpulan data yaitu meminta data sekunder kasus diare pada balita di Kota Palembang Tahun 2016, mengumpulkan data alamat penderita dan melihat adanya indikasi pasien non wilayah kerja, melakukan wawancara mendalam dan telaah dokumen dan menginvestigasi dan mengobservasi faktor lingkungan (sumber air, sampah dan jamban) tempat kasus tertinggi diare pada balita. Hasil penelitian akan dianalisis menggunakan metode Content Analysis. Sedangkan data sekunder akan dianalisis menghasilkan peta menggunakan aplikasi Quantum GIS 1.8.0
Gambar 2. Peta Jumlah Kasus Diare Balita Tahun 2016

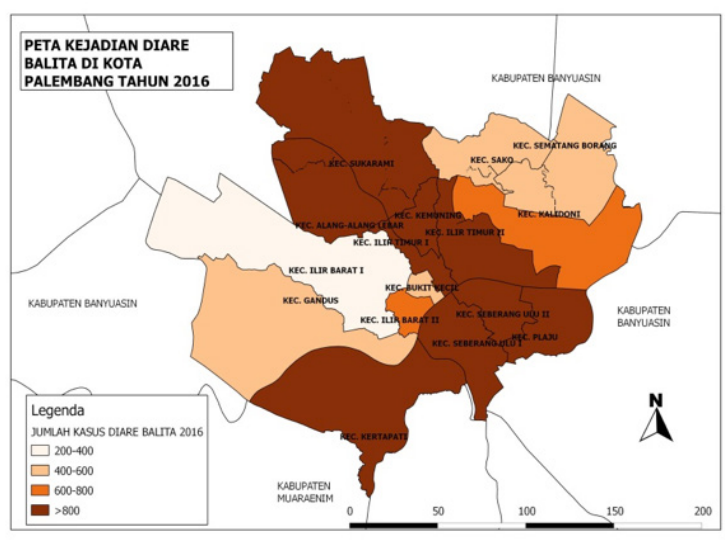

Hasil

Pada gambar 1 diketahui terdapat 9 Kecamatan di Kota Palembang yang termasuk dalam wilayah dengan jumlah kasus diare pada balita tinggi. Kecamatan tersebut adalah Sukarami, Kemuning, Ilir Timur 1 dan 2, Seberang Ulu 1, Seberang Ulu 2, Plaju, Kertapati, dan Kecamatan Ilir Barat 2. Data pada tahun 2016 menunjukkan bahwa kecamatan dengan kasus tertinggi diare berada pada 9 kecamatan namun kecamatan Ilir Barat yang termasuk tinggi pada tahun 2015 digantikan kecamatan Alang-alang lebar yang mengalami peningkatan jumlah kasus ditahun 2016.

Kasus diare di kota Palembang masih didominasi oleh sumbangan daerah yang termasuk daerah dengan sanitasi rendah dan daerah rawa. Nilai cut off point tertinggi digunakan 800 kasus karena diare berpotensi tinggi menyebabkan kematian pada balita sehingga daerah dengan kasus melebihi 800 harus melakukan perbaikan yang intensif dan segera untuk menekan jumlah kasus diare. Tahun 2015, kecamatan dengan kasus diare paling tinggi adalah kecamatan Seberang Ulu I dengan total kasus 2555 kasus diare pada balita dan tahun 2016 Seberang Ulu I masih memiliki angka kasus paling tinggi sekota Palembang dengan jumlah kasus sebanyak 3036 kasus. Posisi berikutnya kejadian diare pada tahun 2015 berada pada kecamatan Ilir Timur 1 dengan kasus sebanyak 1441 sedangkan tahun 2016 posisi tertinggi berpindah kekecamatan Alang-alang Lebar dengan sebanyak 2615 kasus. Pada tahun 2016, 
terdapat anomali data yang cukup besar pada kecamatan Alang-alang Lebar khususnya pada puskesmas Punti Kayu. Terjadi peningkatan sebesar 4 kali lipat jumlah kasus diare dibandingkan tahun 2015. Tahun 2015 kasus diare pada balita di puskesmas Punti Kayu berjumlah 420 kasus dan naik menjadi 1960 kasus ditahun 2016.

Berdasarkan hasil observasi, Masyarakat di wilayah kerja Puskesmas Punti Kayu berada diwilayah pusat kota yang hampir seluruh masyarakat mendapatkan distribusi air dari PDAM setempat dan sudah tidak ada lagi masyarakat yang tidak mempunyai jamban keluarga.

Berdasarkan hasil Investigasi Faktor Penyebab Tingginya Diare di Wilayah Kerja Puskesmas Punti Kayu peneliti menemukan beberapa fakta. Pada tahun 2016, angka diare pada balita di wilayah kerja puskesmas Punti Kayu meningkat 4 kali lipat dibandingkan tahun 2015. Hal ini sebagian besar disebabkan karena sebagian besar bahkan hampir 60-70\% pasien yang berobat ke puskesmas Punti Kayu berasal dari non wilayah kerja puskesmas seperti daerah Sukarame, Sosial, dan Talang Kelapa yang berada di luar kecamatan Alang-alang Lebar. Dikarenakan keterbatasan dalam pendataan dan ketidakterbacaan buku register, diambel sampel beberapa pasien untuk dilihat asal wilayahnya ternyata $60-70 \%$ berada di luar wilayah kerja puskesmas Punti Kayu. Laporan dari klinik, dokter praktek swasta, dan bidan praktek swasta akan ikut ke dalam laporan wilayah kerja puskesmas Punti Kayu jika praktek swasta tersebut berada dalam wilayah kerja. Sehingga potensi pasien yang berasal dari wilayah non kerja puskesmas menjadi lebih besar. Hal ini sebenarnya akan menimbulkan ambiguitas masyarakat yang membaca data diare. "Jumlah kasus yang meningkat itu karena banyak pasien bukan harusnya pasien wilayah sini. Kami kan dak boleh nolak pasien. Selain itu, sekarang lah marak BPJS, jadi kalau masyarakat berobat di klinik swasta deket sini yang kerjasama BPJS. Datanya masuk ke kami. Makanya jadi ningkat berkali-kali lipat"

Penyuluhan dan sosialisasi program kerja diare ke rumah-rumah masyarakat kurang mendapat tanggapan yang positif. Berikut pernyataan bagian promosi kesehatan puskesmas Punti Kayu.
"Sekarang kalau nak sosialisasi atau promosi kesehatan susah, banyaklah ditolak masyarakat. Kami ni lah cak sales dek malah cak penjahat dianggap masyarakat. Baru datang lah ditutup pintu belum jelaske apo-apo. Mungkin kareno itulah dak efektif promosi kesehatan dak jalan sosialisasi kami. Masyarakat dak teredukasi dengan baik”.

Program kerja yang dilakukan oleh puskesmas termasuk kategori monoton selama beberapa tahun terakhir. "kalau program cak-cak itulah dek dari tahun ke tahun. Kami kan melok program dari pusat jadi dak nambah-nambah dewek programnyo. Kalo nak ngembangke dewek dak ktek dananyo dek".

Sebagian besar masyarakat di wilayah kerja Punti Kayu sudah menggunakan PDAM sebagai sumber air. Namun, setelah diselidiki lebih lanjut dan didata masih ada beberapa rumah tangga yang masih mengandalkan sumur gali sebagai sumber air. Dari pemeriksaan sampel sumber air dari sumur gali, beberapa sampel termasuk dalam kategori tidak layak. Masyarakat mengakui sumur yang digunakan hanya sebagai pelengkap. Mereka tetap menggunakan PDAM sebagai sumber air minum. Namun untuk kegiatan lain seperti mencuci dan mandi beberapa masyarakat masih menggunakan sumur gali.

Sistem pelaporan di puskesmas juga masih belum terekap dengan baik. Untuk melihat kasus diare tahun 2016 pada balita diharuskan mengecek dari buku kunjungan tahun 2016 yang jumlahnya sangat banyak. Laporan perekapan per penyakit khususnya diare tidak ditemukan pada tahun 2016. Berikut pernyataan bagian rekam medis puskesmas. "Klo rekapan khusus diare tahun 2016 katek dek kami belum direkap, jadi tegabung di buku kunjungan itulah. Banyak nian datanyo, paling sehalaman buku kunjungan ado sikok duo yang data diare. Data rekapan tahun 2016 dak punyo kami”.

Dari segi sampah dan jamban, sebagian besar penduduk sudah memiliki sistem pembuangan sampah dan jamban yang baik. Namun, memang masih ada beberapa rumah tangga yang secara sanitasi sampah dan jamban masih kurang baik khususnya rumah tangga yang masih berdekatan dengan selokan-selokan besar. 


\section{Pembahasan}

Data distribusi secara spasial dapat lebih mudah dipahami oleh semua kalangan masyarakat dibandingkan data dalam bentuk angka. Sistem informasi geografis memiliki keunggulan yaitu menggabungkan data dengan suatu titik tertentu dibumi dan menghasilkan dalam bentuk peta. Data yang dianalisis secara spasial dapat melihat masalah secara horizontal dan secara geografis. ${ }^{(11)}$ Peta distribusi kasus diare ini menunjukkan bahwa kasus diare pada kota Palembang antara tahun 2015-2016 masih 56\% kecamatan di Kota Palembang termasuk dalam kategori memiliki kasus diare tinggi.

Pada laporan dinas kesehatan hanya disebutkan total kasus tidak ada pemisahan mana kasus yang berasal dari wilayah kerja mana yang diluar wilayah kerja. Kasus yang besar mengindikasikan bahwa program kesehatan tidak berjalan dengan baik. Padahal puskesmas tidak berkewajiban mengintervensi di luar wilayahnya. Sehingga walaupun program di wilayahnya sudah bagus tapi jika banyak pasien dari luar wilayah dan tidak dipisahkan datanya maka citra puskesmas tetap dianggap kurang. Pasien yang berkunjung ke praktek swasta kebanyakan berasal dari daerah non wilayah kerja. Sebagai contoh klinik bersalin dan anak X, menerima pasien dari semua wilayah bahkan sampai wilayah Banyuasin dan Air Batu. Laporan dari klinik ini akan masuk ke dalam kasus tanggung jawab dari puskesmas Punti Kayu. Sehingga, jika ingin menilai keefektifan program kerja puskesmas dengan jumlah kasus diare menjadi tidak relevan. Semakin maraknya Jaminan kesehatan nasional melalui BPJS juga berpotensi semakin meningkatkan jumlah pasien yang berada di non wilayah kerja puskesmas. Puskesmas juga tidak boleh menolak pasien walaupun bukan tertera pada kartu BPJS sebagai faskes tingkat 1 apabila keadaan sedang darurat. Data kesehatan yang terekam dan tersimpan dengan baik akan memudahkan dalam pencarian kembali, pelaporan ke tingkat pusat, integrasi data dan sebagai dasar pembuatan kebijakan yang baik. ${ }^{(8)}$

Upaya puskesmas untuk menyehatkan penduduk di wilayah kerjanya melalui penyuluhan sering tidak direspon masyarakat. Petugas merasa diperlakukan seperti halnya sales penjual barang sehingga ibu-ibu kebanyakan menutup pintu rumahnya saat akan diadakan penyuluhan. Selain itu, petugas juga sering dicurigai oknum kejahatan yang menyamar. Oleh karena itu, program penyuluhan ke rumah-rumah masyarakat menjadi tidak efektif. Sedangkan penyuluhan yang dilakukan di puskesmas dikhawatirkan tidak menjangkau seluruh masyarakat.

Dari segi pengembangan program diare, petugas mengaku program berasal dari pusat sehingga pada level primer hanya ikut program yang sudah dirancang oleh pusat. Padahal setiap daerah punya karakteristik dan keunikan masing-masing yang dapat digali untuk dapat mengefektifkan program. Dana pengembangan program sendiri tidak tersedia, sehingga inovasi dan kreativitas pengembangan program pun hanya akan menjadi sebatas wacana.

Berdasarkan hasil diketahui bahwa saat meminta data ke puskesmas, pihak puskesmas tidak dapat memberikan rekapan kasus diare dan diminta mengecek dari buku kunjungan yang merupakan gabungan dari semua penyakit. Hal ini menunjukkan bahwa sistem informasi kesehatan belum dijalankan dengan maksimal dalam membantu proses perekapan. Padahal fungsi dari sistem informasi kesehatan adalah untuk kemudahan, kecepatan, dan ketepatan dalam pelaporan. ${ }^{(8,11)}$ Puskesmas Punti Kayu memiliki unit SIK namun belum berjalan dengan optimal. Data yang terdapat pada peta sebelumnya didapatkan di dinas kesehatan kota setempat. Namun, saat dilakukan wawancara ke puskesmas, pihak puskesmas mengakui jika data mereka belum direkap dan harus mengecek ke buku register. Saat dikonfirmasi terkait data, pihak mengatakan data berada pada petugas SIK yang lama sehingga mereka kurang tahu dimana laporan rekapannya. Hal ini menunjukkan masih kurangnya kesadaran masyarakat tentang pentingnya data dan program berbasis data. Kepedulian petugas untuk menjaga dan merawat data masih kurang. ${ }^{(11)}$

Selain faktor teknis diatas, peningkatan jumlah kasus di kecamatan Alang-alang Lebar khususnya Puskesmas Punti Kayu juga bergantung pada sanitasi individu. Sehingga walaupun 
tinggal di wilayah perkotaan dimana akses air bersih cukup mudah didapatkan, tersedia jamban keluarga, dan metode pembuangan sampah yang baik, jika individu tidak dapat merawat kebersihan pribadi maka hal tersebut tidak akan berdampak pada pencegahan diare khususnya pada balita. ${ }^{(3,4,6,10,17)}$ Sumber air bersih, jamban keluarga, dan sistem pembuangan sampah yang benar dapat memutus angka kejadian diare. ${ }^{(10,14)}$

\section{Kesimpulan}

Distribusi data secara spasial dapat lebih memudahkan pengambilan keputusan untuk lebih cepat dan tanggap terhadap fenomena kesehatan yang terjadi. Dalam penelitian ini diketahui bahwa Kecamatan Alang-alang Lebar antara tahun 2015-2016 terjadi peningkatan kasus yang tinggi. Kecamatan ini memiliki 2 puskesmas yaitu puskesmas Punti Kayu dan Alang-alang Lebar. Diketahui bahwa peningkatan kasus sebesar 4 kali terjadi di puskesmas Punti Kayu. Penyebab peningkatan ini yaitu sumbangan kasus diare yang bukan masyarakat di wilayah kerja puskesmas Punti Kayu, penerimaan masyarakat terhadap penyuluhan yang kurang, rekap data kurang optimal, dan sanitasi masyarakat yang berdekatan dengan selokan besar masih kurang baik.

Sanitasi individu memegang peranan penting terhadap kasus diare karena di wilayah perkotaan jalan masuk penyakit diare melalui sumber air, jamban dan sampah sudah ditekan melalui fasilitas yang baik. Pemisahan dalam pelaporan menjadi hal penting untuk melihat keefektifan program yang sudah dijalankan oleh puskesmas karena visi puskesmas sendiri sebagai sarana kesehatan primer yang bertugas menyehatkan masyarakat di wilayah kerjanya. Kreativitas petugas dalam mengembangkan program yang sesuai dengan kondisi lingkungan juga harus ditingkatkan sehingga perlu dukungan dari pemerintah terkait penyediaan dana pengembangan.

\section{Ucapan Terima Kasih}

Penulis mengucapkan terimakasih kepada Lembaga Penelitian UNSRI terkait bantuan dana pada penelitian ini dan terimakasih kepada Dekan Fakultas Kesehatan Masyarakat Uni- versitas Sriwijaya atas izin yang diberikan dalam melaksanakan penelitian.

\section{Daftar Pustaka}

1. Abdiana. Determinan Kematian Bayi di Kota Payakumbuh . Jurnal Kesehatan Masyarakat Andalas Vol. 9 No. 2 April 2015 : 88-92

2. Badan Aplikasi Ilmu Pengetahuan dan Teknologi Sriwijaya. Rencana Pembangunan Jangka Panjang (RPJP) Kota Palembang 2005. 2025. Palembang; 2006.

3. Elytha Fauzia. Survey Rumah Tangga PHBS Kota Bukittinggi 20016. Jurnal Kesehatan Masyarakat Andalas Vol. 3 No. 2 September 2009

4. Kamilla Lailla et al. Hubungan Praktek Personal Hygene Ibu dan Kondisi Sanitasi Lingkungan Rumah dengan Kejadian Diare pada Balita di Puskesmas Kampung Dalam Kecamatan Pontianak Timur. Jurnal Kesehatan Lingkungan Indonesia Vol. 11 No 2 Oktober 2012

5. Lailatul M. Ketersediaan Sarana Sanitasi Dasar, Personal Hygiene Ibu Dan Kejadian Diare. J Kesehat Masy. 2013;176-82.

6. Lindayani, Sintari dan R.Azizah. Hubungan Sarana Sanitasi Dasar Rumah dengan Kejadian Diare pada Balita di Desa Ngunut Kabupaten Tulungagung. Jurnal Kesehatan Lingkungan Vol.7 No. 1 Juli 2013: 32-37

7. Kementrian Kesehatan RI. Situasi Diare di Indonesia. Jakarta; 2011.

8. Kementrian Kesehatan RI. Profil Kesehatan Indonesia 2014. Jakarta; 2015.

9. Keputusan Menteri Kesehatan Republik Indonesia Nomor 585/MENKES/SK/V/2007 Tentang Pedoman Pelaksanaan Promosi Kesehatan di Puskesmas

10. Pratama, Riki Nur. Hubungan antara Sanitasi Lingkungan dan Personal Hygene Ibu dengan Kejadian Diare pada Balita di Kelurahan Sumurejo Kecamatan Gunung Pati Kota Semarang. Jurnal Kesmas FKM UNDIP Vol. 2 Nomor 1 Tahun 2013

11. Pusat Data dan Informasi Kementrian Kesehatan RI. Buletin SIKDA Generik. Jakarta; 2011. 
12. Prahasta, Eddy. Konsep-konsep Dasar Sistem Informasi Geografis. Bandung: Informatika Bandung; 2001.

13. Dinas Kesehatan Kota Palembang. Profil Kesehatan Kota Palembang Tahun 2015. Palembang;2015.

14. Sucipto E. Hubungan antara Ketersediaan dan Pemanfaatan Sarana Air Bersih dan Jamban Keluarga dengan Kejadian Diare pada Balita di Puskesmas Sonokidul Kecamatan Kunduran Kabupaten Blora. Universitas Diponegoro Semarang; 2003.

15. Sulistyaningsih. Metodologi Penelitian Kebidanan Kuantitatif-kualitatif. Yogyakarta: Graha Ilmu; 2012.

16. Taosu, Stefen Anyerdy dan R. Azizah. Hubungan Sanitasi Dasar Rumah dan Perilaku Ibu Rumah Tangga dengan Kejadian Diare pada Balita di Desa Bena Nusa Tenggara Timur. Jurnal Kesehatan Lingkungan Vol 7 No. 1Juli 2013: $1-6$

17. Wulandari. Hubungan Faktor Lingkungan dan Faktor Sosio demografi dengan Kejadian Diare Balita di Desa Blimbing Kecamatan Sambirejo Kabupaten Sragen 2009. Universitas Muhammadiyah Surakarta; 2009. 